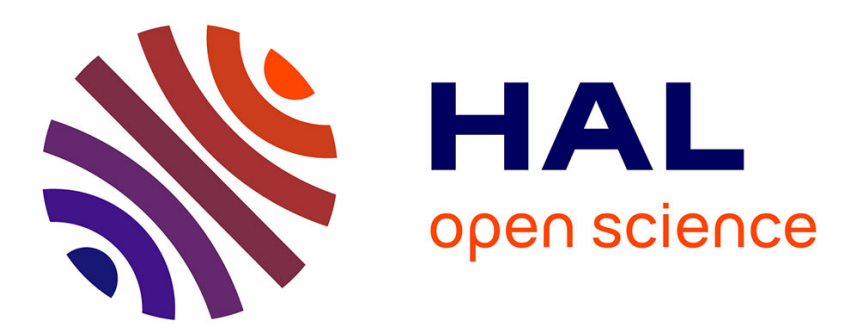

\title{
Fault-diagnosis of PEM fuel cells using electrochemical spectroscopy impedance
}

Raïssa Onanena, Latifa Oukhellou, Etienne Côme, Denis Candusso, Daniel Hissel, Patrice Aknin

\section{> To cite this version:}

Raïssa Onanena, Latifa Oukhellou, Etienne Côme, Denis Candusso, Daniel Hissel, et al.. Faultdiagnosis of PEM fuel cells using electrochemical spectroscopy impedance. Power Plant and Power Systems Control symposium, Sep 2012, Toulouse, France. hal-03223601

\section{HAL Id: hal-03223601 \\ https://hal.science/hal-03223601}

Submitted on 11 May 2021

HAL is a multi-disciplinary open access archive for the deposit and dissemination of scientific research documents, whether they are published or not. The documents may come from teaching and research institutions in France or abroad, or from public or private research centers.
L'archive ouverte pluridisciplinaire HAL, est destinée au dépôt et à la diffusion de documents scientifiques de niveau recherche, publiés ou non, émanant des établissements d'enseignement et de recherche français ou étrangers, des laboratoires publics ou privés. 


\title{
Fault-diagnosis of PEM fuel cells using electrochemical spectroscopy impedance
}

\author{
R Onanena* ***, L Oukhellou*, E Côme*, \\ D Candusso**, D Hissel***, P Aknin* \\ *Paris-Est University, IFSTTAR-GRETTIA, 2 av de la butte verte, 93166 Noisy le Grand Cedex, France \\ ** IFSTTAR, FCLAB Institute, Rue Ernest Thierry-Mieg, 90010 Belfort Cedex, France \\ ***FEMTO-ST UMR CNRS 6174, FCLAB Institute, University of Franche-Comte, 90010 Belfort Cedex, France \\ \{onanena, oukhellou, come, candusso,aknin\}@ifsttar.fr, daniel.hissel@univ-fcomte.fr
}

\begin{abstract}
This paper presents a pattern-recognition-based diagnosis approach for fault-diagnosis of fuel cell stacks, using Electrochemical Impedance Spectroscopy (EIS). It aims at implementing a diagnosis tool able to detect fuel cell degradations from EIS measurements. It consists in different steps. First, measurable features are extracted. Then, in order to improve fault classification, a correlation-based feature selection is used to keep only relevant features. Finally, the classification is achieved to assign each observation to one of the predefined defect classes. The performances are evaluated on an experimental dataset extracted from a twenty-cell PEMFC stack to show the effectiveness of the proposed approach.
\end{abstract}

Keywords: fuel cells, fault diagnosis, electrochemical impedance spectroscopy (EIS), pattern recognition

\section{INTRODUCTION}

The diagnosis of a complex system consists in detecting and identifying defects appearances from inspection measurements. It is particularly vital for industrial systems, in order to avoid premature degradations of the system performances and additional costs. In the case of Fuel Cell (FC) systems, the diagnosis issue is strongly linked with costs, reliability, and durability considerations.

Various diagnosis approaches for FC systems have been developed. These include model-based approaches (Kozlowski et al. 2001; Burford et al. 2004) and gray or black-box model approaches using fuzzy logic (Hissel et $a l$, 2004), neural networks (Nitsche et al, 2004). Non-parametric identification by Markov parameters have also been presented (Tsujioku et al, 2004), as well as a fuzzyclustering-based FC diagnosis approach (Hissel et al, 2007). The last ones use in particular for the information retrieval, the electrochemical impedance spectrometry (EIS). This technique allows measuring the impedance of the investigated system over a large frequency bandwidth. The real and imaginary parts of the system impedance are thus calculated from the measured current and voltage alternating component, and usually the data is presented in a Nyquist plot (Wasterlain et $a l, 2009$ ). EIS measurements not only have the capability to encompass in one representation various information about the state-of-health of the system, but also they can used efficiently to highlight the influence of changes in operating Therefore, the EIS seems to be a powerful tool for the diagnosis process of many systems, including fuel cell (FC) systems.

In this article, the use a pattern-recognition-based methodology for diagnosis purposes is explored, while using EIS measurements as the support database. This particular methodology has the advantage of not requiring any physical modeling of the FC system. With this approach, we aim at detecting faults automatically in the dataset and classify them into different categories. And the main idea that is investigated with this study is that by automatically generating a set of limited descriptors or patterns, one could diagnose fault in FC, while limiting computational costs, reducing information redundancy, and avoiding overfitting. These are factors that need to be taken into account if we want to achieve good performances for the proposed diagnosis approach.

The paper is organized as follows. In section 2, the database on which the analysis is made is presented. The fault diagnosis system will also be briefly presented. In Section 3 the diagnosis methodology is described in more details. And the section 4 presents the results of the study.

\section{DATABASE CONSTITUTION}

The database that was used in this work was built after the experimentation on a twenty-cell PEMFC (Polymer Electrolyte Membrane Fuel Cell) stack, which was operated under various conditions, comparable to real-life conditions, especially when various faults occur. This stack was assembled with commercial perfluorosulfonic MEAs, graphite bipolar plates and electrodes with $100 \mathrm{~cm}^{2}$ area. The experiments and EIS measurements have been performed using a $2 \mathrm{~kW}$ test bench developed in-lab. The experimental generated operating conditions, were based on a fractional experimental design at 2 levels (cf. Table1). This experimental design deals with the impact of five factors on the operating conditions:

- the anodic relative humidity (RHa) [35\%, 75\%],

- the cathodic relative humidity (RHc) $[35 \%, 75 \%]$,

- the anodic stoichiometry factor (FSa) [1.8, 3],

- the cathodic stoichiometry factor (FSc) $[2,3]$, and

- the $\mathrm{FC}$ temperature $(\mathrm{T})\left[60^{\circ} \mathrm{C}, 80^{\circ} \mathrm{C}\right]$. 
The stack is then operated, and faults, from drying to flooding, are triggered by varying one or several parameters. EIS spectra are measured for a current density of $0.5 \mathrm{~A} / \mathrm{cm} 2$. Out of the $2^{5}$ possible experimental conditions (when the 5 factors are modified), only 16 were initially considered, because of their relevance for the initial objectives. But the critical conditions induced by some of these tests on the FC performances and stability, have made impossible to record EIS measurements under the chosen current density. Therefore only 11 experimental points were achieved for that particular current density. These experimental points, obtained with the variations over the five previously mentioned factors, are presented in Table 1

Table 1: Presentation of the different operating conditions and the different factors

\begin{tabular}{|c|l|l|l|l|l|}
\hline $\begin{array}{c}\text { Test } \\
\text { Nb. }\end{array}$ & $\boldsymbol{R H a ( \% )}$ & $\boldsymbol{R H c ( \% )}$ & $\boldsymbol{F S a}$ & $\boldsymbol{F S c}$ & $\begin{array}{l}\boldsymbol{T} \\
\left({ }^{\circ} \boldsymbol{C}\right)\end{array}$ \\
\hline \hline 1 & 35 & 35 & 3 & 2 & 60 \\
\hline 2 & 35 & 75 & 1.8 & 2 & 60 \\
\hline 3 & 35 & 75 & 1.8 & 3 & 80 \\
\hline 4 & 35 & 75 & 3 & 2 & 80 \\
\hline 5 & 35 & 75 & 3 & 3 & 60 \\
\hline 6 & 75 & 35 & 1.8 & 2 & 60 \\
\hline 7 & 75 & 35 & 3 & 2 & 80 \\
\hline 8 & 75 & 75 & 1.8 & 2 & 80 \\
\hline 9 & 75 & 75 & 1.8 & 3 & 60 \\
\hline 10 & 75 & 75 & 3 & 2 & 60 \\
\hline 11 & 75 & 75 & 3 & 3 & 80 \\
\hline
\end{tabular}

Each EIS measurement consists in 42 measurements of the real and imaginary parts, for 42 different frequencies.

In total, 231 impedance spectra were recorded at the outputs of the FC stack, that represent 21 spectra per experience stack (the stack impedance is measured one time, and then, in parallel, each spectrum per individual cell and per experience was recorded (220 impedance spectra in total). More information can be found in (Wasterlain et al, 2009)

Taking into account the analysis presented in (Wasterlain et $a l$, 2009), and taking into consideration the operating parameters, the classification of five failure modes presented in Table 2 will be considered in what follows.

Table 2: Distribution of the data with the corresponding degradation modes

\begin{tabular}{|l|l|l|l|}
\hline Fault mode & gravity & test Nr. & Nr. EIS \\
\hline \multirow{2}{*}{ drying } & moderate & 1,6 & 42 \\
\cline { 2 - 4 } & minor & 7 & 21 \\
\hline Fault-free & & 3 & 21 \\
\hline \multirow{3}{*}{ flooding } & moderate & $2,4,8,10$ & 84 \\
\cline { 2 - 4 } & minor & 5,9 & 42 \\
\cline { 2 - 4 } & slight & 11 & 21 \\
\hline
\end{tabular}

This information about the different failure modes will be important in the following methodology for the identification of data representing a faulty behavior. Indeed, as it will be presented in Section 3.3., each fault mode will be useful as a class label, and for the diagnosis task.

\section{DIAGNOSIS METHODOLOGY}

The proposed methodology consists in three principal steps. First, features are extracted from the initial EIS measurements in order to generate descriptors. Then a feature selection step, where we select a representation space from the extracted features is achieved. This not only enables to remove non-relevant or redundant feature, but it could also increase the quality of the results. And finally for the last step of classification is carried out with the two widely used classifiers: the k-nearest neighbors (k-NN), and the Fisher's Linear Discriminant Analysis (LDA).

\subsection{Feature extraction}

The aim of this step is to select a representation space for the data that will be used in the classification step. This choice of representation space is an essential step for the proposed methodology, because of its potential benefits. Indeed, and these benefits include:

- facilitating data visualization and data understanding - reducing the measurements and storage requirements - reducing training, utilization, and computational times (and errors)

- defying the curse of dimensionality to improve performances (Guyon et al, 2003; and Bishop, 2006).

Rather than using a global fitting of the measurement curve to extract features, the approach adopted here is to directly select points on the spectra and to use them as inputs for the classification step. The main advantage, especially for embedded application, is the fact that these features are measureable features, and require no additional computations for the extraction task.

Using expert knowledge, the feature extraction consists in two different approaches:

- In the first case $\left(\mathrm{FE}_{1}\right)$, features are extracted by selecting out of the EIS spectra couples of a real part and its corresponding imaginary part at a given frequency, the chosen frequency being evenly distributed across the available (measured) frequency bandwidth. The extracted features are the real and imaginary parts of points taken at the frequencies:

- $\mathrm{f}=5 \mathrm{kHz}:\left(R e_{f=5 \mathrm{kHz}} \operatorname{Im}_{f=5 \mathrm{kHz}}\right)$,

- $\mathrm{f}=500 \mathrm{~Hz}:\left(\operatorname{Re}_{f=500 \mathrm{~Hz}} \operatorname{Im}_{f=500 \mathrm{~Hz}}\right)$,

- $\mathrm{f}=50 \mathrm{~Hz}:\left(R e_{f=50 \mathrm{~Hz}} \operatorname{Im}_{f=50 \mathrm{~Hz}}\right)$,

- $\mathrm{f}=5 \mathrm{~Hz}:\left(\operatorname{Re}_{f=5 \mathrm{~Hz}} \operatorname{Im}_{f=5 \mathrm{~Hz}}\right)$, 
- $\quad \mathrm{f}=775 \mathrm{mHz}:\left(\operatorname{Re}_{f=775 \mathrm{mHz}} \operatorname{Im}_{f=775 \mathrm{mHz}}\right)$, and

- $\mathrm{f}=50 \mathrm{mHz}:\left(R e_{f=50 \mathrm{mHz}} \operatorname{Im}_{f=50 \mathrm{mHz}}\right)$.

With this method, a total of 12 features are thus extracted.

- In the second case $\left(\mathrm{FE}_{2}\right)$, particular points or hyperparameters are extracted from the spectra. These represent measures that have been presented as discriminant features in a previous study (Wahdame et $a l, 2008$, Hissel et $a l, 2007)$. These hyperparameters include:

- the internal resistance $\left(R_{\text {int }}\right)$

- the polarization resistance $\left(R_{\text {pola }}\right)$

- the real and imaginary parts of the minimal point $\left(R e_{\text {min }}\right.$ and $\left.I m_{\text {min }}\right)$

- the real and imaginary parts of the breaking point of the spectrum $\left(R e_{\text {break }}, \operatorname{Im}_{\text {break }}\right)$

- the value of the maximal phase $\varphi_{\max }$

This gives 7 extracted features.

In both cases (FE1 and FE2), there are many correlated variables. This shows redundancy in the extracted features. This redundancy could lead to the reduction of the performances of classification methods. Indeed, the amount of data required to obtain a statistically sound result grows exponentially with the dimensionality. Therefore, as the amount of available data is limited, it is necessary to proceed to a dimensionality reduction through a feature selection step.

\subsection{Feature selection}

As presented in section 3.1, the points of the spectra in general and the extracted features in particular, are especially correlated. This could have a negative impact on the results. Therefore, it could be interesting to use a feature selection method that considers this information. The proposed feature selection is a correlation-based method. One of its advantages is to be a pre-processing step independent from the choice of the predictor in the classification step (Kohavi et al, 1997; Guyon, 2003). Correlation-based feature selection method uses hypothesis based on the following heuristic: Good feature subsets contain features highly correlated with the class, yet uncorrelated with each other (Hall, 2000)

The method that was used, is a correlation-based method presented by M. Hall in (Hall, 1999). This correlation-based feature selection (CFS) is a heuristic approach that takes into account the usefulness of individual features for predicting a class label, along with the level of inter-correlation among the features.

The feature selection step is developed as follows:

1. First, for all features, the standard linear correlation coefficient between pairs of variables $(\mathrm{X}, \mathrm{Y})$ are evaluated, and are given by:

$$
r_{X, Y}=\frac{\sum_{i}\left(x_{i}-\bar{x}_{i}\right)\left(y_{i}-\bar{y}_{i}\right)}{\sqrt{\sum_{i}\left(x_{i}-\bar{x}_{i}\right)^{2}} \cdot \sqrt{\sum_{i}\left(y_{i}-\bar{y}_{i}\right)^{2}}}
$$

2. Secondly, for each feature, the class-feature correlation coefficient is evaluated. Because the class attribute is a discrete attribute whereas the features are continuous ones, weighted correlation coefficients are used, and given by the following formula:

$$
r_{C Y}=\sum_{i=1}^{k} p\left(C=c_{i}\right) \cdot r_{X_{b i} Y}
$$

where $X_{b i}$ is a binary attribute that takes value 1 when $X$ has value $\mathrm{x}_{\mathrm{i}}$, and 0 otherwise.

3. Finally, the subset of feature is chosen with the highest heuristic "merit" that quantifies the relevance of a subset, and that is given by:

$$
\text { merit }_{-} s=\frac{k \cdot \bar{r}_{C Y}}{\sqrt{k+k \cdot(k-1) \cdot \bar{r}_{X Y}}}
$$

where $\mathrm{k}$ is the number of selected features in the subset $\mathrm{S}, \bar{r}_{C Y}$ is the mean class-feature correlation $(Y \in S)$, and $\bar{r}_{X Y}$ the average feature-feature intercorrelation. (Guyon, 2003; Hall, 1999, 2000, Ghisselli 1964).

The feature selection procedure, as described above, was applied for the features extracted in the first case (FE1), and the ones extracted in the second case (FE2). This has led to the selection of subsets of relevant features, i.e. features identified as highly correlated with the classes (therefore potentially discriminant for the following classification step), but slightly correlated with each other.

- For FE1, five features were selected: $R e_{f=500 \mathrm{H}}, \operatorname{Im}_{f=500 \mathrm{~Hz}}$, $I m_{f=5 \mathrm{~Hz}}, \operatorname{Im}_{f=775 \mathrm{mHz}}$, and $\operatorname{Im}_{f=5 \mathrm{OmHz}}$.

- For FE2, three features were selected: $R_{\text {int }}, R_{\text {pola }}$ and $\varphi_{\max }$ This subset is particularly interesting, because, Hissel et al (2007), and Wahdame et al (2008), while using approaches different from the approach presented in this paper (fuzzy clustering for the former, and experimental-design-based modeling technique for the latter), have also identified them as relevant features for FC diagnosis.

The scatterplot matrix of the features extracted in the second case is presented in Figure 1. Different colors and markers present each class and its associated data.

In general, a feature \#1 is correlated with another feature \#2 when the data projected on features \#1 and \#2 lead to the representation of the a distinctive pattern such a line. For example, the subplots in the diagonal of the scatterplot matrix correspond to the representation of one parameter versus itself, hence the visualization of a line. On the other hand, when no distinctive pattern is observed, then the corresponding features are uncorrelated. In addition, when clusters of data can be identified on the subplot, the 
valuable classification.

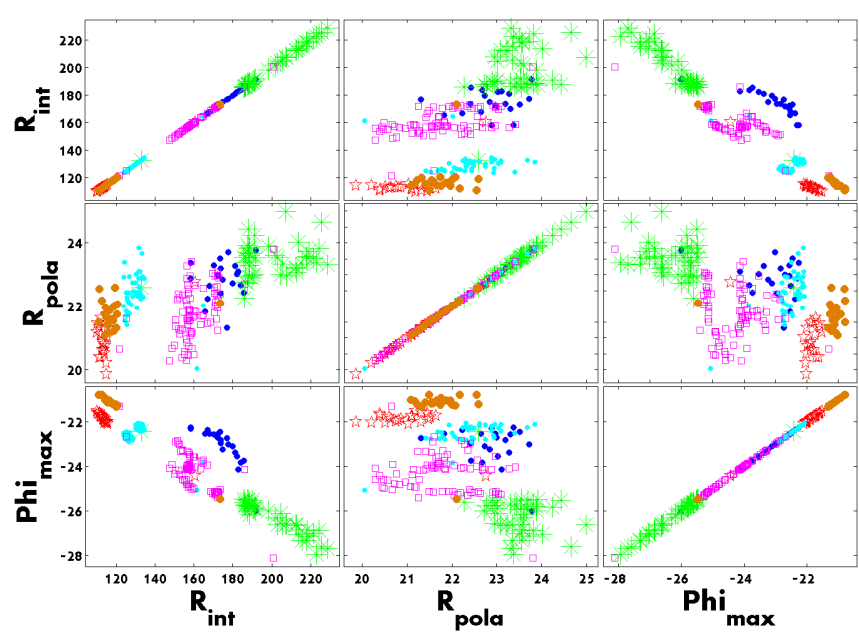

\begin{tabular}{|l|ll|}
\hline$*$ & - & Data in blue correspond of minor drying (Min. D) \\
$*$ & - & Data in green correspond to moderate drying (Mod. D) \\
敒 & - & Data in red correspond to slight flooding (Sli. F) \\
- & - & Data in cyan correspond to minor flooding (Min. F) \\
$\square$ & - & Data in magenta correspond to moderate flooding (Mod. F) \\
& - & Data in orange correspond to the fault-free data (Fault-free) \\
\hline
\end{tabular}

Figure 1: Scatterplot of the different features extracted by the $\mathrm{FE}_{2}$ method

\subsection{Classification methods}

The classification task, final stage of the proposed approach consists in assigning labels on new data (test set), based labeled training data. This process is divided into a learning phase, where the classification method is trained on a training data, and a test phase, where the classifier obtained in the training phase is used to label new data. In the case of the present dataset, labels correspond to the gravity of the fault modes (e.g. minor drying, fault-free mode, etc.), and the dataset is impedance spectra of the FC, represented by the representation space chosen in Section 3.2.

For this classification task, two methods have been tested: the multiclass linear discriminant analysis and the k-nearest neighbor rule.

Linear discriminant analysis (Bo et al, 2002; Hastie et al, 2001)

The classification algorithm that is used here is a multiclass linear discriminant analysis (LDA); it learns linear boundaries in the input space by assuming that each class is modeled by one probability density, and all probability densities have the same covariance matrix.

\section{$k$ nearest neighbor classifier}

Unlike the LDA, the k-nearest neighbor (k-NN) classifier is a distance-based supervised classifier which only considers the neighborhood around the data point we want to classify. In the case of $\mathrm{k}=1$, the $\mathrm{k}-\mathrm{NN}$ algorithm works as follows. Given a set $D=\left\{\left(x_{1}, x_{2}\right), \ldots,\left(x_{n}, y_{n}\right)\right\}$ of labeled data, to determine the class of the test point $\mathrm{x}$, the method searches $x_{j}$, the nearest point to $x$ with regard to a chosen metric (in our case the Euclidian distance):

$$
j=\underset{i}{\arg \min }\left\|x-x_{i}\right\|
$$

The nearest-neighbor rule for classifying $\mathrm{x}$ is to assign it the label associated with $x_{j}$. Then $\left(x, y_{j}\right)$ is the solution. In the case of $\mathrm{k}$ nearest neighbors, $\mathrm{k}$ of the nearest neighbors are gathered, a vote is proceeded, and the class of the most neighbors wins. This means that the $\mathrm{kNN}$ classifies a data example according to a majority vote of its $\mathrm{k}$ nearest data examples with regard to a chosen metric.

\section{RESULTS AND DISCUSSION}

The classified training data consists of $n_{1}=174$ EIS measurements and the test dataset of $n_{2}=57$ EIS measurements; this is ratio of $75 \%$ and $25 \%$ from the total database. A cross-validation approach was adopted to assess the performance of each classifier (Bo et al, 2002). The database was randomly split into four subsets; we used three of them as the training set to learn the classifier, and the remaining subset was used as the test set to estimate the performances obtained with the trained classifier. These two steps were repeated four times, each time leaving out a different subset for testing. The results were averaged over the four test sets.

The results were analyzed according to the global classification error (in \%) and the confusion matrices between the true and the estimated classes for all the observations in the database. The results obtained with the two feature extractions methods (FE1, FE2) and the two classifiers (LDA, kNN) are reported in Tables [3-6]. In these tables, the rows correspond to the true class, whereas the columns correspond to the predicted class. To analyze the performances of a classification task, one looks at the two numbers:

-false positive rate: these rates are given by the elements of a row of the confusion matrix that are not the diagonal ones. The false positive rate is the proportion of negative cases (i.e. data points that belong to other classes than the assigned one) that are incorrectly classified as positive;

-true positive rate: corresponding to the numbers given by the diagonal numbers of the matrix, the true positive rate is the proportion of positive cases (i.e. data points that actually belong to a given class) that are classified correctly as positive. 
The results reveal good classification performances despite some misclassification between contiguous classes: the falsepositive rate is low, both when the LDA or the $\mathrm{kNN}$ classifiers are used. Indeed, they present for most classes very high values for true positive rates, and small values for false positive rates. Furthermore, false positive rates appear between classes that are close with regard to the gravity of the degradation; for example in Table 4, 4.8\% of slight flooding defects is classified wrongly as belonging to the fault-free class. This tends to confirm the expert analysis of the degradations of the stack, i.e. degradation classes can be put in a graduation scale. It can be observed that the $\mathrm{kNN}$ classifier using the FE1 features gives the highest classification rate $(99.6 \%)$.

Table 3: Results obtained with the nearest neighbor classifier combined with the first feature extraction method (FE1)

\begin{tabular}{|c|c|c|c|c|c|c|c|}
\hline & & \multicolumn{6}{|c|}{ Predicted Class } \\
\hline & $\begin{array}{l}\text { classif. } \\
\text { rate }(\%)\end{array}$ & $\begin{array}{l}\text { Mod. } \\
\text { D }\end{array}$ & $\begin{array}{l}\text { Min. } \\
\text { D }\end{array}$ & $\begin{array}{l}\text { Fault- } \\
\text { free }\end{array}$ & $\begin{array}{l}\text { Sli. } \\
\text { F }\end{array}$ & $\begin{array}{l}\text { Min. } \\
\text { F }\end{array}$ & $\begin{array}{l}\text { Mod } \\
\text {. F }\end{array}$ \\
\hline \multirow{7}{*}{ 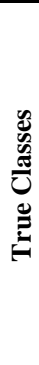 } & Mod. D & 100 & 0 & 0 & 0 & 0 & 0 \\
\hline & Min. D & 0 & 100 & 0 & 0 & 0 & 0 \\
\hline & Fault-free & 0 & 0 & 100 & 0 & 0 & 0 \\
\hline & Sli. F & 0 & 0 & 4.8 & 95.2 & 0 & 0 \\
\hline & Min. F & 0 & 0 & 0 & 0 & 100 & 0 \\
\hline & Mod. F & 0 & 0 & 0 & 0 & 0 & 100 \\
\hline & $\begin{array}{l}\text { Global } \\
\text { Accuracy }\end{array}$ & \multicolumn{6}{|c|}{$\begin{array}{l}\text { test error rate }(\%): \mathbf{9 9 . 6} \\
\text { Nr. of nearest neighbors: } 1 \\
\text { Selected features: }\left[\boldsymbol{R} \boldsymbol{e}_{f=500 \mathrm{H}}\right.\end{array}$} \\
\hline
\end{tabular}

Table 4: Results obtained with the linear discriminant analysis classifier combined with the first feature extraction method (FE1)

\begin{tabular}{|c|c|c|c|c|c|c|c|}
\hline & & \multicolumn{6}{|c|}{ Predicted Classes } \\
\hline & $\begin{array}{l}\text { classif. } \\
\text { rate }(\%)\end{array}$ & $\begin{array}{l}\text { Mod } \\
\text {.D } \\
\end{array}$ & $\begin{array}{l}\text { Min. } \\
\text { D }\end{array}$ & $\begin{array}{l}\text { Fault- } \\
\text { free }\end{array}$ & $\begin{array}{l}\text { Sli. } \\
\text { F }\end{array}$ & $\begin{array}{l}\text { Min. } \\
\text { F }\end{array}$ & $\begin{array}{l}\text { Mod } \\
\text {.F }\end{array}$ \\
\hline \multirow{7}{*}{$\underbrace{0}_{0}$} & Mod. D & 100 & 0 & 0 & 0 & 0 & 0 \\
\hline & Min. D & 0 & 100 & 0 & 0 & 0 & 0 \\
\hline & Fault-free & 0 & 0 & 95.2 & 4.8 & 0 & 0 \\
\hline & Sli. F & 0 & 0 & 4.8 & 95.2 & 0 & 0 \\
\hline & Min. F & 0 & 0 & 0 & 0 & 100 & 0 \\
\hline & Mod. F & 0 & 0 & 0 & 0 & 0 & 100 \\
\hline & $\begin{array}{l}\text { Global } \\
\text { Accuracy }\end{array}$ & \multicolumn{6}{|c|}{$\begin{array}{l}\text { test error rate }(\%): \mathbf{9 9 . 1} \\
\text { training error rate }(\%): \mathbf{9 8 . 9} \\
\text { Selected features : }\left[\boldsymbol{R e}_{f=500 \mathrm{H}_{z}}, \boldsymbol{I m}_{f=500 \mathrm{H}_{z},}, \boldsymbol{I m}_{f=5 \mathrm{~Hz}}\right. \\
\left.\qquad \operatorname{Im}_{f=775 \mathrm{mHz}}, \boldsymbol{I m}_{f=50 \mathrm{mHz}} \cdot\right] \\
\text { merit value } \mathbf{0} \mathbf{0 . 5 3}\end{array}$} \\
\hline
\end{tabular}

Table 5: Results obtained with the nearest neighbor classifier combined with the second feature extraction method (FE2)

\begin{tabular}{|c|c|c|c|c|c|c|c|}
\hline & & \multicolumn{6}{|c|}{ Predicted Classes } \\
\hline & $\begin{array}{l}\text { classif. } \\
\text { rate }(\%)\end{array}$ & $\begin{array}{l}\text { Mod. } \\
\text { D }\end{array}$ & $\begin{array}{l}\text { Min. } \\
\text { D }\end{array}$ & $\begin{array}{l}\text { Fault- } \\
\text { free }\end{array}$ & $\begin{array}{l}\text { Sli. } \\
\text { F }\end{array}$ & $\begin{array}{l}\text { Min. } \\
\text { F }\end{array}$ & $\begin{array}{l}\text { Mod. } \\
\text { F }\end{array}$ \\
\hline \multirow{7}{*}{ 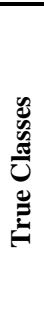 } & Mod. D & 97.6 & 0 & 0 & 0 & 2.4 & 0 \\
\hline & Min. D & 4.8 & 85.7 & 0 & 0 & 0 & 9.5 \\
\hline & Fault-free & 0 & 0 & 95.2 & 0 & 0 & 4.8 \\
\hline & Sli. F & 0 & 0 & 4.8 & 90.5 & 0 & 4.8 \\
\hline & Min. F & 0 & 0 & 0 & 0 & 95.2 & 4.8 \\
\hline & Mod. F & 1.2 & 1.2 & 1.2 & 0 & 1.2 & 95.2 \\
\hline & $\begin{array}{l}\text { Global } \\
\text { Accuracy }\end{array}$ & \multicolumn{6}{|c|}{$\begin{array}{l}\text { test error rate }(\%): \mathbf{9 4 . 3} \\
\text { Nr. of nearest neighbors: } 3 \\
\text { Selected features }:\left[\boldsymbol{R}_{\text {int }}, \boldsymbol{R}_{\text {pola }}, \varphi_{\max }\right] \\
\text { merit value }: \mathbf{0 . 3 8}\end{array}$} \\
\hline
\end{tabular}

Table 6: Results obtained with the linear discriminant analysis classifier combined with the second feature extraction method (FE2)

\begin{tabular}{|c|c|c|c|c|c|c|c|}
\hline & & \multicolumn{6}{|c|}{ Predicted Classes } \\
\hline \multirow{8}{*}{ 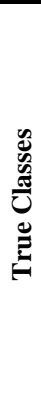 } & $\begin{array}{l}\text { classif. } \\
\text { rates }(\%)\end{array}$ & $\begin{array}{l}\text { Mod. } \\
\text { D }\end{array}$ & $\begin{array}{l}\text { Min. } \\
\text { D }\end{array}$ & $\begin{array}{l}\text { Fault- } \\
\text { free }\end{array}$ & $\begin{array}{l}\text { Sli. } \\
\text { F }\end{array}$ & $\begin{array}{l}\text { Min. } \\
\text { D }\end{array}$ & $\begin{array}{l}\text { Mod. } \\
\text { D }\end{array}$ \\
\hline & Mod.D & 97.6 & 0 & 0 & 0 & 2.4 & 0 \\
\hline & Min. D & 4.8 & 95.2 & 0 & 0 & 0 & 0 \\
\hline & Fault-free & 0 & 0 & 95.2 & 0 & 0 & 4.8 \\
\hline & Sli. F & 0 & 0 & 0 & 95.2 & 0 & 4.8 \\
\hline & Min. F & 0 & 0 & 2.4 & 4.8 & 88.0 & 4.8 \\
\hline & Mod.F & 1.2 & 1.2 & 1.2 & 1.2 & 1.2 & 94.0 \\
\hline & $\begin{array}{l}\text { Global } \\
\text { Accuracy }\end{array}$ & \multicolumn{6}{|c|}{$\begin{array}{l}\text { test error rate }(\%): \mathbf{9 3 . 9} \\
\text { training error rate }(\%): \mathbf{9 3 . 1} \\
\text { Selected features }:\left[\boldsymbol{R}_{\text {int }}, \boldsymbol{R}_{\text {pola }}, \boldsymbol{\varphi}_{\max }\right] \\
\text { merit value } \mathbf{0} \mathbf{0 . 3 8}\end{array}$} \\
\hline
\end{tabular}

\section{CONCLUSIONS}

This article has presented a pattern recognition PEM fuel cell fault diagnosis approach that uses EIS measurements. It involves first a feature extraction step, during which, points are extracted from the EIS spectra. This helps later to facilitate data visualization and problems linked to the phenomenon of curse dimensionality. A selection procedure to keep only relevant features then takes place and the last phase of classification gives the fault diagnosis of the studied data. Because of the correlation and redundant issues, particularly linked to the evolution of the spectra with the fault occurrences, a correlation-based feature selection criterion had to be used.

Simulations on actual data set have shown that a very high accuracy for fault prediction can be achieved, and can be as high as $99 \%$. However, because all the data were extracted from only one PEM fuel cell stack, further studies must be 
carried out with more data, containing if possible, information from various kinds of stacks. This could lead to a generic approach of PEM fuel cell diagnosis.

\section{ACKNOWLEDGMENT}

This research was supported by the French National Agency for Research (ANR project DIAPASON2)

\section{REFERENCES}

Bishop, C.M. (2006). Pattern recognition and machine learning, Springer, (Bishop, 2006)

Bo, T.H., Jonassen, I. (2002). New feature subset selection procedures for classification of expression profiles. Genome Biology 3(4), 0017.1-0017.11

Burford D., Davis, T., and Mench, MM. (2004), Real-time electrolyte temperature measurement in an operating polymer electrolyte fuel cell. Adv. Mater. Fuel Cells Batteries Symp. Proc. Adv. Mater. Fuel Cells Batteries Symp., 204th Electrochem. Soc. Meeting.

Ciureanu, M., Roberge, R. (2001). Electrochemical Impedance Study of PEM Fuel Cells. Experimental Diagnostics and Modeling of Air Cathodes, Journal of Physical Chemistry (105), pp. 3531-3539.

Duda, R.O., Hart, P.E., and Stork, D.G. (2001). Pattern classification (2nd ed.), John Wiley and Sons.

Fukunaga, K.(1992). Introduction to Statistical Pattern Recognition (2nd edition), Academic Press Inc., New York.

Ghiselli, E. E. (1964), Theory of Psychological Measurement. McGraw-Hill Book Company.
Guyon I. and Elissee A. (2003). An introduction to variable and feature selection. Journal of Machine Learning Research, (3), pp. 1157-1182.

Hall, M.A. (2000) Correlation-based Feature Selection for Discrete and Numeric Class Machine Learning, Proceedings of the 17th International Conference on Machine Learning (ICML2000), Stanford, CA,, pp. 359-366.

Hall, M. A. (1999), Correlation- based feature subset selection. PhD dissertation, Department of Computer Science, University of Waikato.

Hissel, D., Candusso, D., Harel, F. (2007). Fuzzy Clustering Durability Diagnosis of Polymer Electrolyte Fuel-Cells dedicated to transportation applications, IEEE Trans. on Vehicular Technology (56), pp.2414-2420.

Hissel, D., Péra, M. C., and Kauffmann, J.M.. (2004). Diagnosis of automotive fuel cell power generators. $J$. Power Sources, 128(2), pp.239-246.

Kohavi, R., John, G.H. (1997). Wrappers for feature subset selection. Artificial Intelligence 97(1-2), pp.273-324.

Kozlowski, J.D., Byington, C.S., Garga, A. K., Watson, M. J., and T. A. Hay, (2001). Model-based predictive diagnostics for electrochemical energy sources. IEEE Aerosp. Conf.

Nitsche, C., Schroedl, S., and Weiss, W. (2004) Onboard diagnostics concept for fuel cell vehicles using adaptive modelling. IEEE Intell. Veh. Symp., Parma, Italy.

Tsujioku, Y., Iwase, M., and Hatakeyama, S. (2004) Analysis and modelling of a direct methanol fuel cell for failure diagnosis. IEEE IECON Conf., Busan, Korea,

Wahdame, B., Candusso, D., Harel, Fabien, F., Xavier, Péra, M. C., Hissel, D., Kauffmann, J.M. (2008). Analysis of a PEMFC durability test under low humidity conditions and stack behaviour modelling using experimental design techniques, Journal of Power Sources 182(2), pp 429-440 